\title{
A Mass Spectrometric Study on the in Vitro Methylation of HMGA1a and HMGA1b Proteins by PRMTs: Methylation Specificity, the Effect of Binding to AT-Rich Duplex DNA, and the Effect of C-Terminal Phosphorylation ${ }^{\dagger}$
}

\author{
Yan Zou, ${ }^{\ddagger}$ Kristofor Webb, ${ }^{\S}$ Avi D. Perna, ${ }^{\ddagger}$ Qingchun Zhang, ${ }^{\ddagger}$ Steven Clarke,$\S$ and Yinsheng Wang*,‡ \\ Department of Chemistry-027, University of California, Riverside, California 92521-0403, and Department of Chemistry and \\ Biochemistry, Molecular Biology Institute, University of California, Los Angeles, California 90095-1560
}

Received December 3, 2006; Revised Manuscript Received March 19, 2007

\begin{abstract}
HMGA1a and HMGA1b are members of one subfamily of non-histone chromosomal highmobility group (HMG) proteins. They bind to various DNA-related substrates, including the minor groove of AT-rich duplex DNA sequences, and have been postulated to be architectural transcription factors functioning in a wide variety of cellular processes. Post-translational modifications of HMGA1 proteins, such as phosphorylation, acetylation, and methylation, are widely observed in tumor cells in vivo and correlated with the modulation of protein function. Here, we investigated the in vitro methylation of recombinant human HMGA1a and HMGA1b proteins by three members of the protein arginine methyltransferase (PRMT) family: PRMT1, PRMT3, and PRMT6. PRMT1 and PRMT3 showed a preference for methylating arginine residues in the first AT-hook of HMGA1 proteins, whereas PRMT6 methylated mainly residues in the second AT-hook. The initial sites of methylation catalyzed by PRMT1 and PRMT3 were mapped by tandem mass spectrometry to be Arg25 and Arg23, respectively, while we confirmed that the initial sites of methylation catalyzed by PRMT6 were at Arg57 and Arg59. Our results also revealed that binding of HMGA1 proteins to AT-rich duplex DNA, but not GC-rich duplex DNA, significantly inhibited the methylation efficiency of all of the PRMTs toward HMGA1 proteins. Moreover, C-terminal constitutive phosphorylation of HMGA1 proteins induced by protein kinase CK2 did not have any appreciable effect on the in vitro methylation of HMGA1. Our results suggest that PRMT1 might be involved in the previously reported methylation of Arg25 in HMGA1a in vivo.
\end{abstract}

The high-mobility group (HMG) ${ }^{1} \mathrm{~A} 1$ proteins, including HMGA1a and HMGA1b, are among a group of non-histone chromosomal proteins that function in a wide variety of cellular processes, including gene regulation, cell growth, differentiation, chromatin remodeling, apoptosis, and neoplastic transformation $(1-3)$. These proteins share characteristic structural properties, i.e., three highly conserved DNA-binding motifs (so-called "AT-hooks") and an acidic C-terminal motif (Figure 1). HMGA1 proteins bind to various DNA-related substrates, such as nucleosomes $(4,5)$, fourway junctions (6), supercoiled DNA (7), and the minor groove of AT-rich duplex DNA sequences (8). In addition, the HMGA1 proteins recognize substrate structure rather than

\footnotetext{
† This work was supported by the National Institutes of Health (Grants GM026020 to S.C. and CA101864 to Y.W.)

* To whom correspondence should be addressed. E-mail: yinsheng.wang@ucr.edu. Fax: (951) 827-4713. Telephone: (951) 8272700.

University of California, Riverside.

$\S$ University of California, Los Angeles.

${ }^{1}$ Abbreviations: HMG, high-mobility group; PTM, post-translational modification; CK2, protein kinase CK2 (or casein kinase 2); PRMT, protein arginine methyltransferase; CARM, coactivator-associated arginine methyltransferase; MMA, $N^{\mathrm{G}}$-monomethylarginine; aDMA, asymmetric $N^{\mathrm{G}}, N^{\mathrm{G}}$-dimethylarginine; sDMA, symmetric $N^{\mathrm{G}}, N^{\prime \mathrm{G}}$ dimethylarginine; AdoMet, $S$-adenosyl-L-methionine; ODN, oligodeoxynucleotide; FRAP, fluorescence recovery after photobleaching; ESI, electrospray ionization; MALDI, matrix-assisted laser desorption/ ionization; TOF, time-of-flight; MS/MS, tandem mass spectrometry; TFA, trifluoroacetic acid.
}

nucleotide sequence. Although they exhibit little, if any, secondary structure while free in solution, HMGA1 proteins adopt a specific conformation upon binding to DNA substrates and alter the structure of DNA and chromatin after binding $(2,9)$.

The most characteristic structural features of HMGA1 proteins are the three AT-hooks that share similar peptide sequences, including a Pro/Gly-Arg-Gly-Arg-Pro sequence flanked by positively charged lysine/arginine residues on both sides. This AT-hook peptide motif is highly conserved in evolution and is also found in many other proteins, such as transcription factors or components of chromatin remodeling complexes (2). The two isoforms of HMGA1 proteins, HMGA1a $(\sim 11.5 \mathrm{kDa}, 106$ amino acids) and HMGA1b ( $\sim 10.5 \mathrm{kDa}, 95$ amino acids), stem from the translation of the splicing variants of a single gene (HMGAl) and differ only in that HMGA1b protein has an 11-residue internal deletion in the linker segment between the first and second AT-hook DNA-binding motifs $(10,11)$. The two protein isoforms are thus almost identical except the different spacing along the protein chains results in the two proteins being able to establish interactions with differently spaced ATrich DNA regions (12). Moreover, these two isoform proteins exhibit different biological functions in vivo $(13,14)$.

Previous work suggested that HMGA1 proteins are subjected to various post-translational modifications (PTMs), including phosphorylation, methylation, acetylation, and ADP 
A

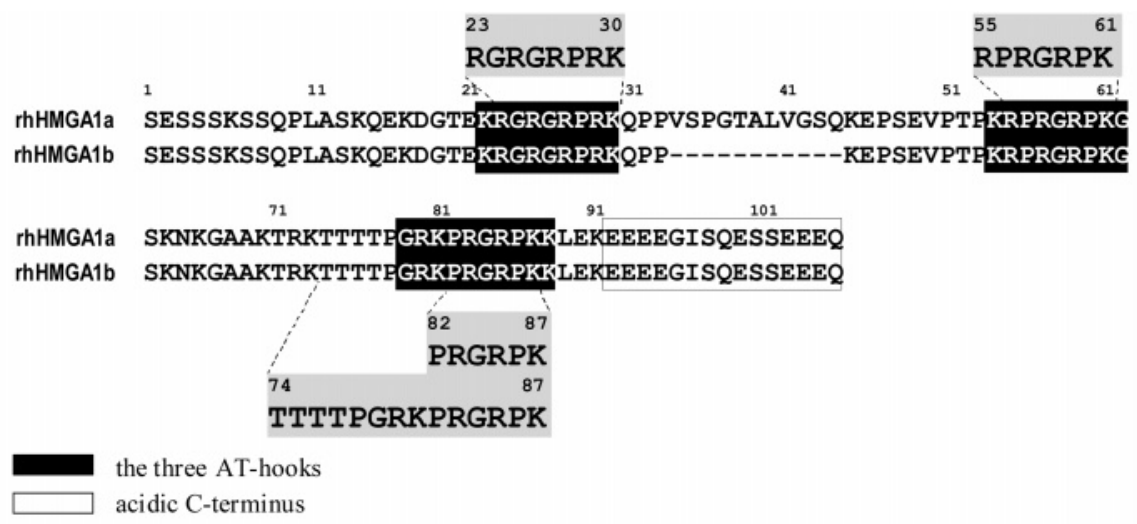

B
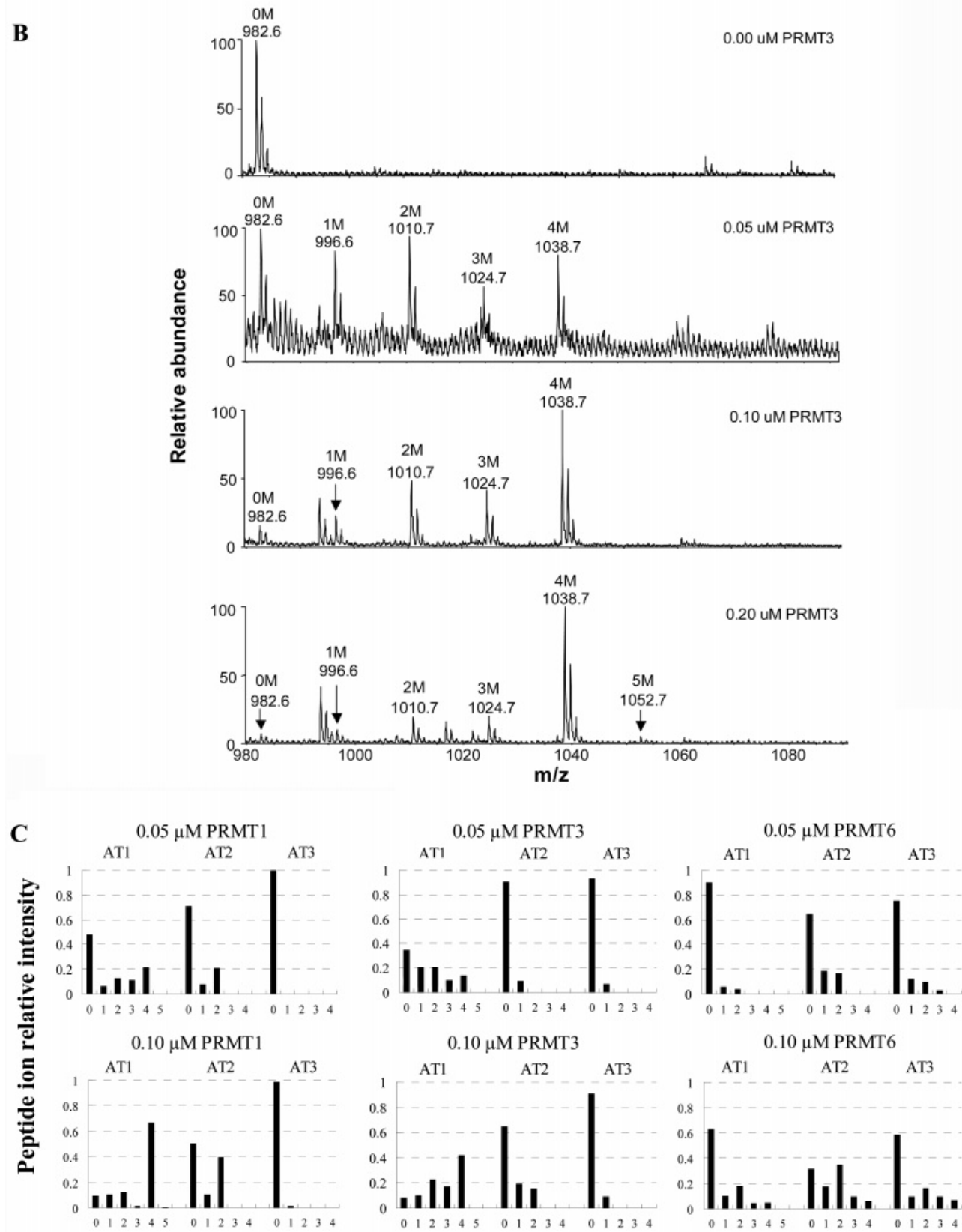

Number of methyl groups

FIgURE 1: All three AT-hooks of rhHMGA1a and -b are methylated by PRMT1, PRMT3, and PRMT6 in vitro. (A) Protein sequences of HMGA1a and -b and the three AT-hook peptides produced by Lys-C digestion. The sequences highlighted in gray represent the peptides containing the DNA-binding AT-hooks. (B) The first AT-hook peptide 23-30 was methylated by PRMT3 in vitro. (C) Histograms showing the relative abundances of peptide ions carrying different numbers of methyl groups at all three AT-hooks of rhHMGA1a. The methylation was induced by PRMT1, PRMT3, and PRMT6 at two different concentrations $(0.05$ and $0.10 \mu \mathrm{M})$. 
ribosylation $(12,15-21)$. In this respect, several protein kinases have been demonstrated to be involved in the prevalent phosphorylation of HMGA1 proteins. Protein kinase CK2 can catalyze the constitutive phosphorylations of Ser98, Ser101, and Ser102 at the acidic C-termini of HMGA1a and HMGA1b proteins in vivo and in vitro (2224). In addition, Thr52 and Thr77 in HMGAla were shown to be phosphorylated in a cell cycle-dependent manner in vivo $(25,26)$ and by cdc2 kinase in vitro (25). The phosphorylation of Thr20, Ser43, and Ser63 in HMGA1a was catalyzed by protein kinase $\mathrm{C}-\alpha(\mathrm{PKC} \alpha)$ in vivo and in vitro (17). The function of the phosphorylation induced by these kinases is not clearly understood, though the phosphorylation in various regions of HMGA1 proteins reduces, to different extent, the binding affinity of the proteins for DNA $(12,15,25-27)$.

Arginine methylation, a type of PTM that is drawing an increasing amount of attention recently (28), was also detected in HMGA1 proteins. In this respect, the monomethylation of Arg25 in HMGA1a was correlated with the execution of apoptosis in cancer cells (16). More recently, we reported that Arg25 in HMGA1a, but not HMGA1b, could be mono- and dimethylated, and both symmetric and asymmetric dimethylations were observed (29). Different PTM patterns, including arginine methylation on the HMGA1a and HMGA1b proteins isolated from certain non-metastatic and metastatic cell types, were observed, suggesting that the two isoforms likely elicit distinct biological functions (13).

The methylation of arginine residues is catalyzed by protein arginine methyltransferases (PRMTs), which transfer a methyl group from $S$-adenosyl-L-methionine (AdoMet) to the terminal nitrogen atoms of guanidinium side chains of arginine residues of a protein substrate. Eight human PRMTs have been characterized. They are classified as type I and type II enzymes, which catalyze the formation of asymmetric $N^{\mathrm{G}}, N^{\mathrm{G}}$-dimethylarginine (aDMA) and symmetric $N^{\mathrm{G}}, N^{\prime} \mathrm{G}_{-}$ dimethylarginine (sDMA), respectively $(28,30-32)$. Moreover, both types of enzymes can methylate arginine residues to form monomethylarginine (MMA), presumably as an intermediate for the formation of DMA. Among the mammalian PRMTs that have been identified, PRMT1, PRMT3, PRMT4/CARM1 (coactivator-associated arginine methyltransferase 1), PRMT6, and PRMT8 are suggested to be type I methyltransferases $(28,30,32-34)$, whereas PRMT5/JBP1 (Janus kinase-binding protein) and possibly PRMT7 are type II enzymes $(31,35)$. PRMT2 was identified by sequence homology; however, no methyltransferase activity has been found for this protein (36). Several type I and type II PRMTs have been tested for their methylation activities on HMGA1 proteins, and the results suggested that PRMT6 might be a good candidate enzyme for the in vivo methylation of HMGA1 proteins $(37,38)$. In vitro, PRMT6 methylates HMGA1a primarily in the second AT-hook at Arg57 and Arg59; a small amount of methylation is observed in the first AT-hook and at Arg83 and Arg85 in the third AT-hook (38). Which arginine residues in HMGA1 proteins methylated by other PRMTs has not been examined. From the observation that the Arg25 residue in the first AT-hook was the only site of methylation in HMGA1a extracted from many tumor cell lines $(16,29)$, we suspected that there might be other PRMTs that could methylate the HMGA1a protein preferentially at $\operatorname{Arg} 25$.
In this study, we examined in vitro methylation of recombinant human HMGA1a (rhHMGA1a) and HMGA1b (rhHMGA1b) proteins by PRMT1, PRMT3, and PRMT6. Considering that HMGA1 proteins can bind to AT-rich DNA stretches in vitro and undergo conformational change upon DNA binding $(2,9)$, we also investigated the in vitro methylation of rhHMGA1 proteins in the presence of duplex DNA. Multiple forms of PTMs, such as phosphorylation, acetylation, and methylation, are often observed simultaneously in HMGA1 proteins under various physiological conditions in vivo $(13,39,40)$. However, the correlation among different PTMs of HMGA1 proteins remains unknown, though the existence of a PTM "code" for HMGA1 proteins has been proposed (38). Therefore, we also examined the effect of phosphorylation of HMGA1 proteins on the PRMT-catalyzed methylation of HMGA1 proteins.

\section{EXPERIMENTAL PROCEDURES}

Materials. GST fusion proteins of PRMT1 (41), PRMT3 (42), and PRMT6 (32) were obtained as described previously. Full-length recombinant human HMGA1a (rhHMGA1a) and HMGA1b (rhHMGA1b) proteins were overexpressed in Escherichia coli BL21 DE3 pLysS cells (Invitrogen) and extracted by using $5 \%$ perchloric acid as previously described $(43,44)$. The rhHMGA1 proteins were further purified on an Ultrafast Microprotein Analyzer HPLC system (Michrom BioResources Inc., Auburn, CA) by using a $4.6 \mathrm{~mm} \times 250$ mm C4 column (Grace Vydac, Hesperia, CA). A $72 \mathrm{~min}$ gradient from 12 to $25 \% \mathrm{CH}_{3} \mathrm{CN}$ in a $0.1 \%$ aqueous solution of trifluoroacetic acid (TFA) was employed. The fractions containing rhHMGA1 protein were pooled, dried, and further purified by a $50 \mathrm{~min}$ gradient from 10 to $18 \% \mathrm{CH}_{3} \mathrm{CN}$ in a $0.1 \%$ aqueous solution of TFA. The flow rate was $1.0 \mathrm{~mL} /$ $\mathrm{min}$, and protein was detected by absorbance at $220 \mathrm{~nm}$. The purified proteins were then quantified by a Bradford protein assay (Bio-Rad, Hercules, CA) using bovine serum albumin as a standard.

To examine the effects of duplex DNA on the methylation of HMGA1 proteins, a 36-mer AT-rich oligodeoxynucleotide (ODN) d(CCA CTG CCC GGC ACA GAA ATA ACA ACC ACG GTT ACT) (24) and its complementary strand (obtained from IDT, Coralville, IA) were used. A control experiment was also carried out with a GC-rich duplex DNA sequence, d(CCA CTG CCC GGC ACA GGG GCG GCA ACC ACG GTT ACT), and its complementary strand.

In Vitro Phosphorylation of rhHMGAla and rhHMGAlb Proteins by Protein Kinase CK2. To prepare the C-terminally phosphorylated HMGA1 proteins, we carried out an in vitro phosphorylation reaction by incubating approximately $15 \mu \mathrm{g}$ of rhHMGA1 proteins with 600 units of protein kinase CK2 (New England Biolabs, Beverly, MA) and $200 \mu \mathrm{M}$ ATP in $150 \mu \mathrm{L}$ of a $1 \times$ reaction buffer supplied by the vendor. The reaction mixture was incubated at $37{ }^{\circ} \mathrm{C}$ for $1 \mathrm{~h}$. The phosphorylated rhHMGA1 proteins were purified by HPLC with a $0.5 \mathrm{~mm} \times 150 \mathrm{~mm} \mathrm{C4}$ capillary column (Grace Vydac) on an Agilent 1100 system (Agilent Technologies, Palo Alto, CA) monitored by absorbance at $220 \mathrm{~nm}$. A 50 min gradient from 5 to $30 \% \mathrm{CH}_{3} \mathrm{CN}$ in $0.1 \%$ TFA was employed at a flow rate of $10 \mu \mathrm{L} / \mathrm{min}$. The samples were then dried in a Speedvac concentrator and quantified again by a Bradford protein assay. 
Table 1: Unmodified and Methylated Peptide Ions Detected in the MALDI Mass Spectra Corresponding to the Three AT-Hooks from HMGA1a and -b Proteins ${ }^{a}$

\begin{tabular}{|c|c|c|c|c|c|c|c|c|c|c|}
\hline \multirow[b]{2}{*}{ AT-hook } & \multirow[b]{2}{*}{ peptide, sequence } & \multicolumn{9}{|c|}{$\mathrm{m} / \mathrm{z}$ values of observed peptide ion } \\
\hline & & $0 \mathrm{M}$ & $1 \mathrm{M}$ & $2 \mathrm{M}$ & $3 \mathrm{M}$ & $4 \mathrm{M}$ & $5 \mathrm{M}$ & $6 \mathrm{M}$ & $7 \mathrm{M}$ & $8 \mathrm{M}$ \\
\hline AT1 & 23-30, RGRGRPRK & 982.6 & 996.6 & 1010.7 & 1024.7 & 1038.7 & 1052.7 & 1066.8 & 1080.8 & 1094.8 \\
\hline AT2 & 55-61, RPRGRPK & 866.6 & 880.6 & 894.6 & 908.6 & 922.7 & 936.7 & 950.7 & - & - \\
\hline \multirow[t]{2}{*}{ AT3 } & 82-87, PRGRPK & 710.6 & 724.6 & 738.6 & 752.6 & 766.7 & - & - & - & - \\
\hline & 74-87, TTTTPGRKPRGRPK & 1552.9 & 1566.9 & 1580.9 & 1594.9 & 1609.0 & 1623.0 & 1637.0 & - & - \\
\hline
\end{tabular}

${ }^{a}$ M, methylation; AT, AT-hook. Relatively high levels of methylation for some peptides could be due to the "overmethylation" at high enzyme: substrate ratios.

In Vitro Methylation of Recombinant and Phosphorylated HMGA1 Proteins. rhHMGA1 or phosphorylated human HMGA1 (PA1) proteins $(0.5 \mu \mathrm{M})$ were incubated with different concentrations $(0.00,0.05,0.10$, and $0.20 \mu \mathrm{M})$ of GST-PRMT fusion proteins and $100 \mu \mathrm{M}$ AdoMet (SigmaAldrich, St. Louis, MO) in $10 \mathrm{mM}$ sodium phosphate buffer (pH 7.5) at $37^{\circ} \mathrm{C}$ overnight. To examine the effect of DNA binding on the methylation reactions, incubations were carried out under the same conditions except that the recombinant or phosphorylated HMGA1a and -b proteins $(0.5 \mu \mathrm{M})$ were preincubated with $0.5 \mu \mathrm{M}$ duplex DNA at $37^{\circ} \mathrm{C}$ in $10 \mathrm{mM}$ sodium phosphate buffer for $1 \mathrm{~h}$. GSTPRMT fusion proteins $(0.25 \mu \mathrm{M})$ and AdoMet $(100 \mu \mathrm{M})$ were then added, and the reaction was continued overnight. Methylated rhHMGA1 proteins were purified by HPLC as described above.

Enzymatic Digestion. Sequencing-grade Lys-C and modified trypsin were purchased from Roche Applied Science (Indianapolis, IN). Unmodified or methylated HMGA1 proteins were digested with Lys-C in $50 \mathrm{mM} \mathrm{NH}_{4} \mathrm{HCO}_{3}(\mathrm{pH}$ 8.1) at $37{ }^{\circ} \mathrm{C}$ overnight. A high enzyme-to-substrate ratio (1:3 by weight) was used to minimize missed cleavages, thereby facilitating the subsequent semiquantification of the level of methylation. To determine the phosphorylation sites in HMGA1 proteins, in vitro phosphorylated HMGA1 proteins $(1 \mu \mathrm{g})$ were digested with trypsin at an enzyme: substrate ratio of $1: 10$ in a $50 \mathrm{mM} \mathrm{NH}_{4} \mathrm{HCO}_{3}$ solution $(\mathrm{pH}$ 8.1) at $37^{\circ} \mathrm{C}$ overnight. The digestion mixtures were dried, desalted by $\mathrm{C} 18$ ZipTip treatment (Millipore, Billerica, MA), and subjected to mass spectrometric analysis.

Mass Spectrometry and Data Processing. Matrix-assisted laser desorption/ionization (MALDI)-MS measurements were performed on a QSTAR XL quadrupole/time-of-flight mass spectrometer equipped with an o-MALDI ion source (Applied Biosystems, Foster City, CA). The mass accuracy in MS/MS mode was approximately $10-30 \mathrm{ppm}$ with external calibration. Lys-C-digested peptides were dissolved in an aqueous solution of $0.1 \%$ TFA and mixed with an equal volume of a matrix solution, consisting of a saturated solution of $\alpha$-cyano-4-hydroxycinnamic acid in a solvent mixture of $\mathrm{CH}_{3} \mathrm{CN}, \mathrm{H}_{2} \mathrm{O}$, and TFA (50:50:0.1, v/v/v).

Methylation was quantified by assuming that methylation of arginine residues does not change appreciably the ionization efficiency of the peptide. Peptides containing all three AT-hooks of HMGA1 proteins can be detected in the Lys-C digestion mixture. From the intensities of monoisotopic peaks of different forms of a peptide (unmodified and methylated), we could estimate the relative levels of methylation of the three AT-hooks in HMGA1 proteins. For instance, we used the ratio of the monoisotopic peak of monomethylated peptide 23-30 over the sum of those of the unmodified and methylated forms of peptide $23-30$ to represent the relative degree of monomethylation of the first AT-hook.

The sites of phosphorylation of HMGA1 proteins induced by protein kinase CK2 were examined by on-line LCelectrospray ionization (ESI)-MS/MS. A $0.50 \mathrm{~mm} \times 250$ mm Zorbax C18 capillary column (300 A pore size, $5 \mu \mathrm{m}$ particle size, Agilent Technologies) was used. The flow rate was $6 \mu \mathrm{L} / \mathrm{min}$, and a $63 \mathrm{~min}$ gradient from 2 to $65 \% \mathrm{CH}_{3}$ $\mathrm{CN}$ in a $0.6 \%$ aqueous solution of acetic acid was employed. The effluent from the HPLC column was directed to an LTQ linear ion trap mass spectrometer (Thermo Electron, Inc., Waltham, MA). Mass calibration for the LTQ mass spectrometer was carried out with standards provided by the instrument vendor, including caffeine, the tetrapeptide MRFA, and Ultramark 1621 . The spray voltage was $4.0 \mathrm{kV}$, and the capillary temperature was maintained at $275^{\circ} \mathrm{C}$. MS/MS was conducted in both data-dependent scan mode and pre-selected precursor ion mode. The mass width for precursor ion isolation was $3 \mathrm{~m} / \mathrm{z}$ units, and the collision gas was helium. The LC-MS/MS data were analyzed with a SEQUEST search of the Swissprot protein database using BioWorks version 3.2 (Thermo Electron, Inc.).

\section{RESULTS}

All Three AT-Hooks of rhHMGAla and -b Are Methylated by GST-PRMT1, GST-PRMT3, and GST-PRMT6 Fusion Proteins with Different Site Preferences. Previous in vitro methylation studies of rhHMGAla protein showed that among the five PRMTs that were tested (PRMT1, PRMT3, PRMT4, PRMT6, and PRMT7), only PRMT1, PRMT3, and PRMT6 could methylate the HMGA1a protein $(37,38)$. Here, we carried out an in vitro methylation reaction of rhHMGA1a and A1b proteins with a range of concentrations of GST-PRMT1, GST-PRMT3, and GST-PRMT6 fusion proteins. After HPLC purification and extensive endoproteinase Lys-C digestion, MALDI-MS of the resulting digestion mixtures from methylation reactions of all three PRMTs showed protonated ions of unmodified and differently methylated peptides corresponding to all three AT-hooks from rhHMGA1a and rhHMGA1b (Table 1). Because the deletion of 11 residues that distinguishes HMGA1a from HMGA1b occurs in the linker region between the first and second AT-hooks, Lys-C digestions of both isoforms give identical peptide segments containing the individual AThooks (Figure 1A). We then quantified the methylation level within the first and second AT-hooks on the basis of peptides containing residues 23-30 (unmodified, $\mathrm{m} / \mathrm{z}$ 982.7) and residues 55-61 (unmodified, $\mathrm{m} / \mathrm{z}$ 866.6), respectively. Because of the incomplete cleavage of the amide linkage 
between Lys81 and Pro82, we found two peptides bearing the third AT-hook: residues 82-87 (unmodified, $m / z$ 710.6) and residues 74-87 (unmodified, $\mathrm{m} / \mathrm{z}$ 1552.9). The ion abundances for both peptide segments were used to calculate the level of methylation for the third AT-hook.

Figure 1B illustrates the use of MALDI-MS to monitor the extent of methylation of arginine in the first AT-hook (designated as AT1) of rhHMGA1a induced by PRMT3. As expected, only the $[\mathrm{M}+\mathrm{H}]^{+}$ion of unmodified peptide $23-$ $30(\mathrm{~m} / \mathrm{z}$ 982.6) was observed when no PRMT3 was added $(0.00 \mu \mathrm{M})$. In the methylation reaction with $0.05 \mu \mathrm{M}$ PRMT3, we observed mono- $(\mathrm{m} / \mathrm{z}$ 996.6), di- $(\mathrm{m} / \mathrm{z}$ 1010.7), tri- $(\mathrm{m} / \mathrm{z}, 1024.7)$, and tetramethylation $(\mathrm{m} / \mathrm{z}, 1038.7)$ of peptide 23-30. With the increment of enzyme concentration, the methylated forms of the peptide become dominant as revealed by MALDI-MS. Similarly, the second and third AThooks (AT2 and AT3, respectively) of rhHMGA1a can be methylated by all three PRMTs (Figure 1C).

Most interestingly, the specificities of methylation among the three AT-hooks induced by PRMT1 and PRMT3 are different from those induced by PRMT6 (Figure 1C). Consistent with previous findings (38), PRMT6 methylates rhHMGA1a primarily in the second AT-hook at Arg57 and Arg59, to a reduced level in the third AT-hook at Arg83 and Arg85, and at a very low level at the first AT-hook. In this respect, we fragmented the protonated ion of the second and third AT-hook peptides with a lower level of methylation, and the initial methylation sites were located at Arg57 and Arg59 at the second AT-hook (Figure S1 of the Supporting Information), followed by Arg83 and Arg85 at the third AT-hook (Figures S2 and S3 of the Supporting Information) in the rhHMGA1a protein.

We chose to use MS/MS of the $[\mathrm{M}+\mathrm{H}]^{+}$ion of dimethylated peptide segment $82-87\left(\mathrm{PR}_{83} \mathrm{GR}_{85} \mathrm{PK}, \mathrm{m} / \mathrm{z}\right.$ 738.5 , Figure S2) to illustrate the assignment of the methylation site. In this context, we found the neutral loss of a dimethylamine $\left[\mathrm{HN}\left(\mathrm{CH}_{3}\right)_{2}, 45 \mathrm{Da}\right]$ from the precursor and a number of sequence ions, which supports the presence of an aDMA in this peptide (29). In addition, the neutral losses of 31 and $56 \mathrm{Da}$ fragments were not detectable in this spectrum, excluding the presence of monomethylation in this peptide (29). Moreover, we observed the $b_{3}, b_{4}$, and $y_{4}$ ions in both the unmodified and dimethylated forms, i.e., $b_{3} / b_{3}{ }^{2 M}$ (m/z 311.3/339.3), $\mathrm{b}_{4} / \mathrm{b}_{4}{ }^{2 \mathrm{M}}\left(\mathrm{m} / \mathrm{z}\right.$ 467.3/495.4), and $\mathrm{y}_{4} / \mathrm{y}_{4}{ }^{2 \mathrm{M}}(\mathrm{m} / \mathrm{z}$ 457.4/485.3; Figure S2), whereas the $b_{5}$ ion was found to be only in the dimethylated form (i.e., $b_{5}{ }^{2 \mathrm{M}}+\mathrm{H}_{2} \mathrm{O}$ and $\mathrm{b}_{5}{ }^{2 \mathrm{M}}$ $+\mathrm{H}_{2} \mathrm{O}-45, \mathrm{~m} / \mathrm{z} 610.5$ and 565.4). These results support the idea that dimethylation is heterogeneously distributed between Arg83 and Arg85. A similar conclusion can be drawn from the MS/MS analysis of the $[\mathrm{M}+\mathrm{H}]^{+}$ion of dimethylated peptide TTTTPGRKPRGRPK (Figure S3 gives the MS/MS data for the same peptide segment from HMGA1b). In this respect, it is worth noting that Arg80 in this peptide can also be weakly methylated as supported by the observation of both penta- and hexamethylated peptide segment 74-87 [TTTTPGRKPRGRPK (Table 1)].

PRMT1 and PRMT3, however, methylate rhHMGA1a preferentially at the first AT-hook, to a lesser extent at the second AT-hook, and at a minimum level at the third AThook. In vitro methylation reactions using the rhHMGA1b isoform with the three enzymes gave generally similar results with respect to the methylation selectivity among the three

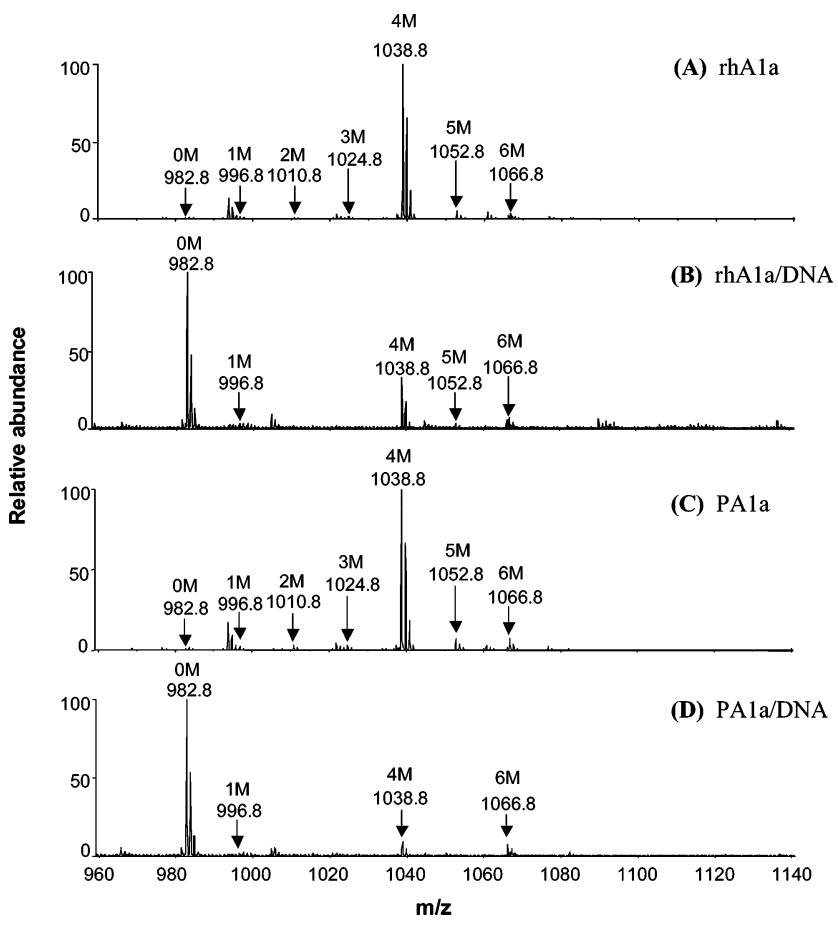

FIGURE 2: MALDI mass spectra of the first AT-hook peptide 2330 of rhHMGA1a (rhA1a) (A and B) and C-terminally phosphorylated HMGA1a (PA1a) (C and D) that were methylated in vitro by PRMT3 in the absence (A and C) or presence (B and D) of AT-rich duplex DNA.

AT-hooks. However, PRMT3 methylates the third AT-hook of rhHMGA1b to a much weaker degree than rhHMGA1a. Moreover, no methylation was observed for the third AThook of rhHMGA1b by PRMT1 under our experimental conditions (Figure 3A,B).

Binding to AT-Rich, Double-Stranded DNA Substantially Decreases the Methylation Efficiency of PRMTs toward rhHMGAl Proteins. Native HMGA1a and -b proteins are mainly random coil in solution, while they adopt specific conformations upon binding to the minor grove of AT-rich DNA $(9,45)$. We then asked whether binding to DNA may alter the methylation of the HMGA1a and HMGA1b proteins. To this end, we examined the methylation of rhHMGA1a and rhHMGA1b in the presence of d(CCA CTG CCC GGC ACA GAA ATA ACA ACC ACG GTT ACT)/ d(AGT AAC CGT GGT TGT TAT TTC TGT GCC GGG CAG TGG). This DNA sequence was part of the human germ line $\mathrm{G} \epsilon$ promoter and was shown previously to be able to bind to rhHMGA1a and -b (24). We first incubated rhHMGA1a or rhHMGA1b with duplex AT-rich DNA at 1:1 molar ratio at $37^{\circ} \mathrm{C}$ for $1 \mathrm{~h}$. We then subjected the resulting protein-DNA complex to in vitro methylation reactions with PRMT1, -3 , and -6 , isolated the HMGA1 proteins from the reaction mixture by HPLC, and analyzed the Lys-C digestion mixtures by MALDI-MS. In Figure 2, we show the results from the PRMT3 methylation reaction mixtures; we observed the presence of a major tetramethylated peptide species $23-30(\mathrm{~m} / \mathrm{z} 1038.8$ ion $)$ in the absence of AT-rich duplex DNA, while the unmethylated form of this peptide $(\mathrm{m} / \mathrm{z}, 982.8$ ion $)$ predominates in the presence of AT-rich duplex DNA (compare panels A and C with panels $\mathrm{B}$ and D).

We then employed the relative abundances of ions corresponding to unmethylated as well as all forms of 

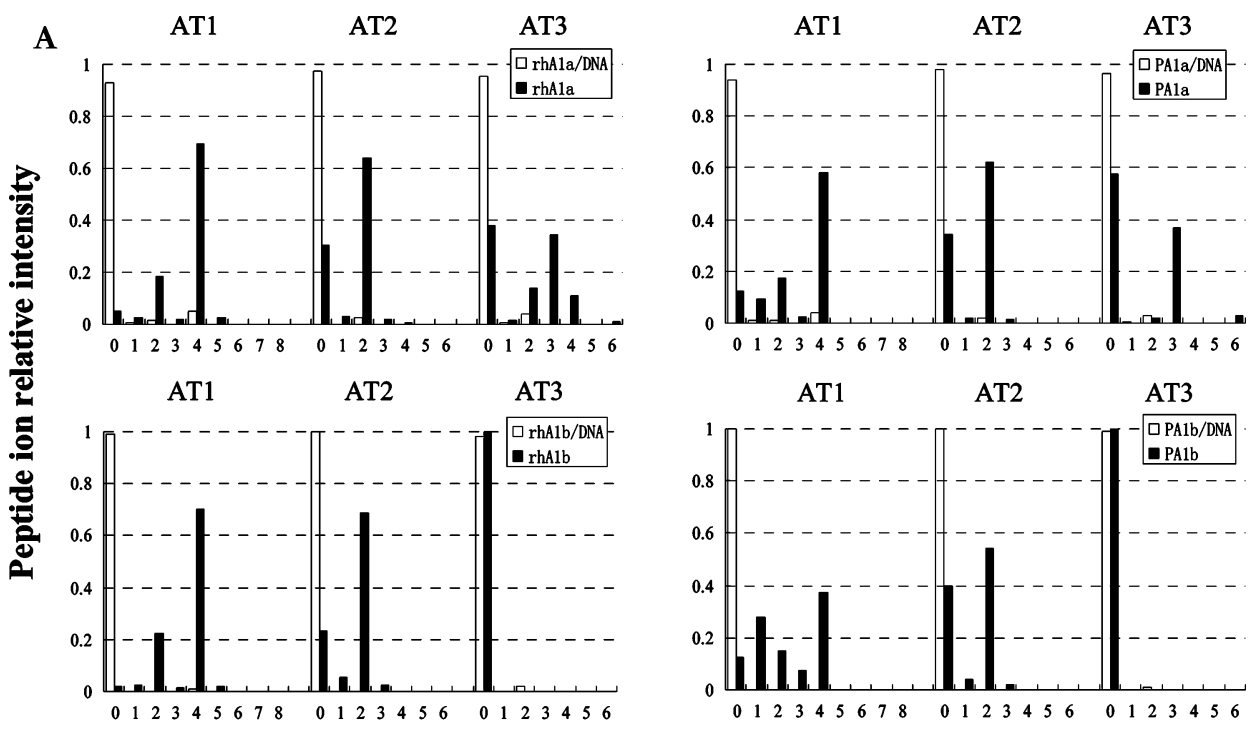

Number of methyl groups
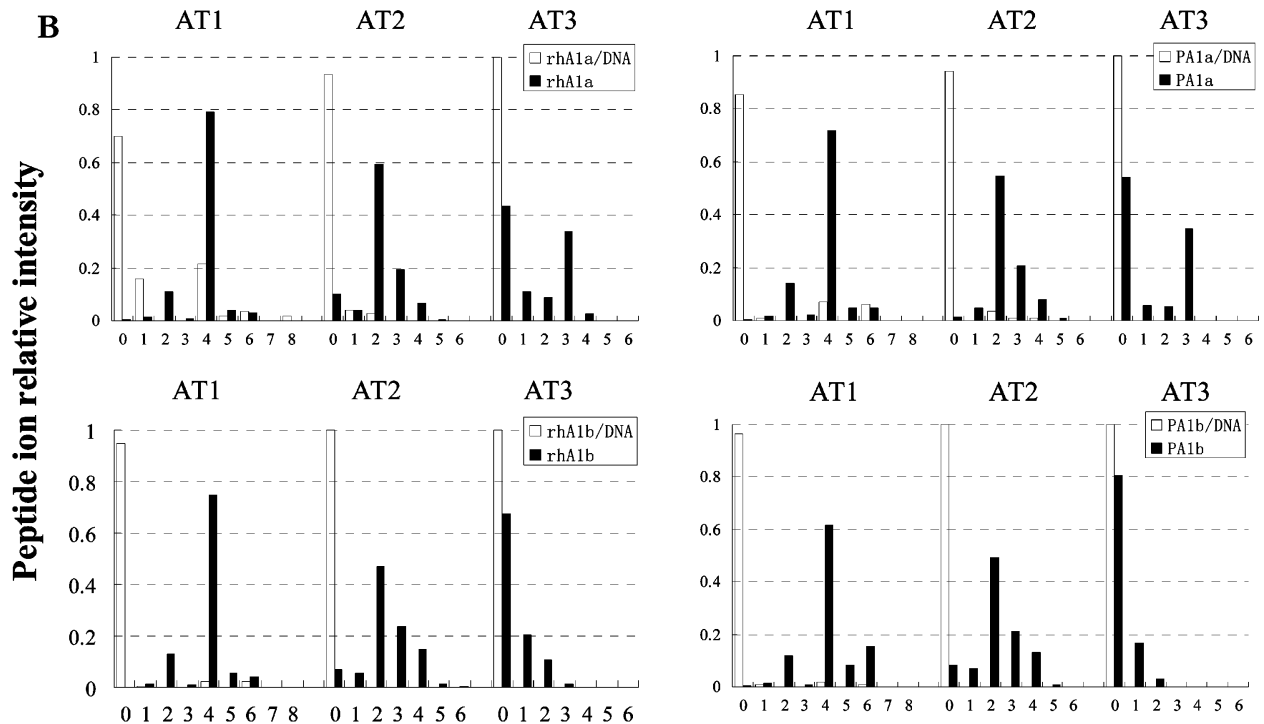

Number of methyl groups
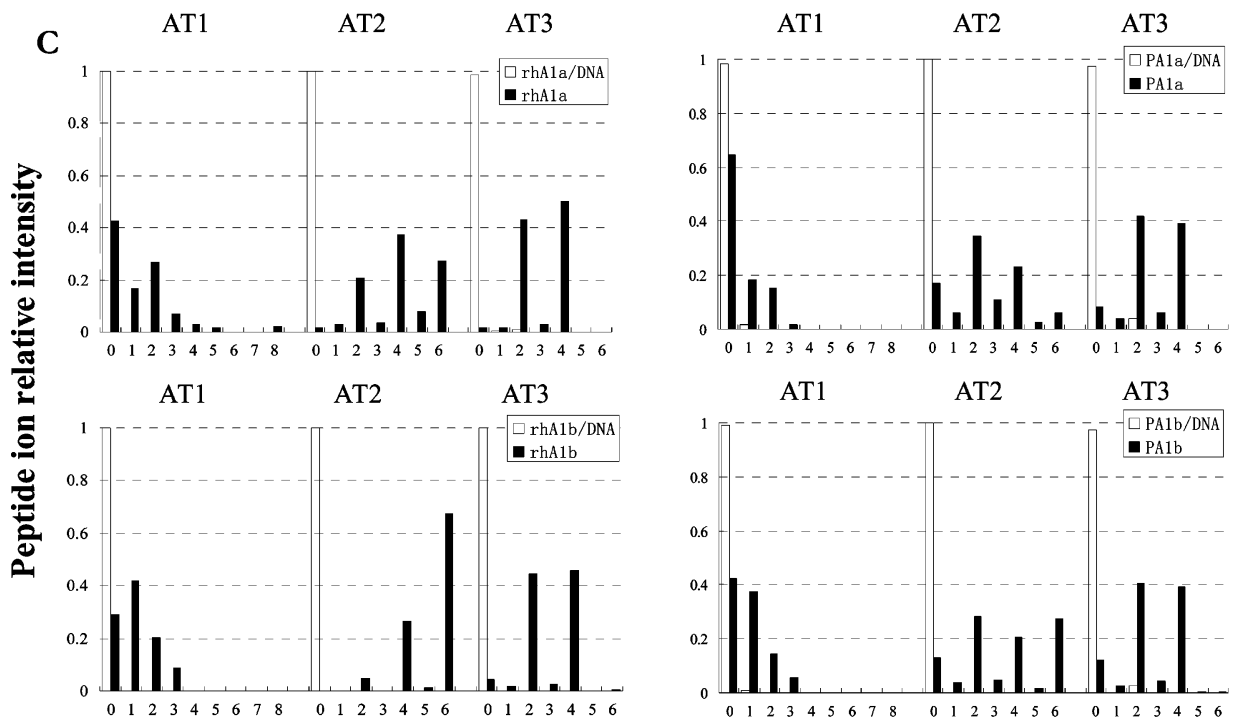

Number of methyl groups

FIGURE 3: Histograms showing the relative abundances of peptide ions carrying different numbers of methyl groups at all three AT-hooks of rhHMGA1a (rhA1a), C-terminally phosphorylated HMGA1a (PA1a), rhHMGA1b (rhA1b), and C-terminally phosphorylated HMGA1b (PA1) by PRMT1 (A), PRMT3 (B), and PRMT6 (C) in the presence (white bars) or absence (black bars) of AT-rich duplex DNA. 


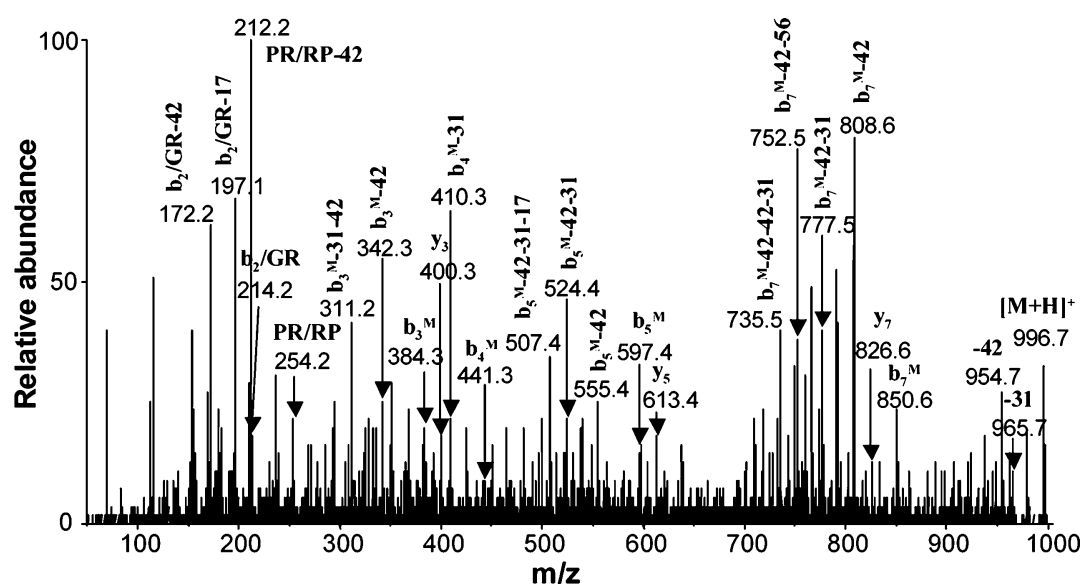

FIGURE 4: Product ion spectrum of the MALDI-produced $[\mathrm{M}+\mathrm{H}]^{+}$ion $\left(\mathrm{m} / \mathrm{z}\right.$ 996.7) of monomethylated AT1 peptide $23-30\left(\boldsymbol{R}_{23}\right.$ GRGRPRK) showing that Arg23 in rhHMGA1a can be methylated by PRMT3. Neutral losses are indicated in the spectrum. The ions bearing a monomethylarginine are marked with an $\mathrm{M}$. The neutral losses of 17, 31, 42, and $56 \mathrm{Da}$ fragments correspond to the losses of $\mathrm{NH}_{3}$, $\mathrm{CH}_{3} \mathrm{NH}_{2}, \mathrm{C}(\mathrm{NH})_{2}$, and $\mathrm{CH}_{3} \mathrm{~N}=\mathrm{C}=\mathrm{NH}$ groups, respectively (see ref 29 ).

methylated peptides to calculate the percentage of individual methylation forms for each of the three PRMTs (see Experimental Procedures). We found that binding to ATrich duplex DNA inhibits significantly the methylation of rhHMGA1 proteins catalyzed by each enzyme (Figure 3AC). In Figure 3A, showing results with the PRMT1 enzyme, 93\% of the first AT-hook peptide of rhHMGA1a was unmodified after binding to DNA, whereas only $5 \%$ remained unmethylated in the absence of AT-rich duplex DNA. The second and third AT-hook peptide of rhHMGA1a was also methylated to a low extent $(2-4 \%)$ by PRMT1 in the presence of AT-rich DNA duplex. The methylation of rhHMGA1b by PRMT1 (Figure 3A) was almost completely abolished in the presence of AT-rich duplex DNA. In the case of in vitro methylation by PRMT3, as depicted in Figure $3 \mathrm{~B}$, the first AT-hook of rhHMGA1a is preferentially methylated, to $30 \%$, in the presence of AT-rich duplex DNA; in contrast, the first AT-hook of rhHMGA1b was only methylated to approximately $5 \%$. Thus, in the presence of AT-rich duplex DNA, rhHMGA1a is a better substrate than rhHMGA1b by both PRMT1 and PRMT3. The methylation of both rhHMGA1a and rhHMGA1b by PRMT6, however, was almost completely abolished in the presence of AT-rich duplex DNA (Figure 3C). To confirm this result, we also obtained the MALDI-MS data of intact (undigested) rhHMGA1a methylated by PRMT6 in the absence or presence of AT-rich duplex DNA. As shown in Figure S4 of the Supporting Information, we observed the expected mass shift of the protein due to methylation only in the absence of AT-rich duplex DNA; no shift was found when the AT-rich duplex DNA was present in the reaction mixture.

To further establish that the abrogation of methylation of rhHMGA1 proteins by PRMTs was due to the binding of the proteins to the AT-rich region of the duplex DNA, we carried out the in vitro methylation reaction of rhHMGA1a by all three PRMTs in the presence of another duplex DNA, in which the central six $\mathrm{A} \cdot \mathrm{T}$ base pairs in the original DNA sequence were replaced with six $\mathrm{G} \cdot \mathrm{C}$ base pairs (GC-rich DNA; see Experimental Procedures). Not surprisingly, the GC-rich duplex DNA exhibited no apparent inhibition of the in vitro methylation of rhHMGA1a protein catalyzed by any of the three PRMTs (Figure S5 of the Supporting Information). Thus, we conclude that the inhibition of in vitro methylation of rhHMGA1 proteins is due to the specific binding of the AT-rich region of the double-stranded DNA to HMGA1 proteins.

Protein Kinase CK2-Mediated Phosphorylation of HMGA1 Proteins Does Not Change the Methylation Efficiency of PRMTs toward rhHMGA1 Proteins. To investigate the effect of C-terminal phosphorylation of HMGA1a and -b on the in vitro methylation reaction, we generated the phosphorylated HMGA1a and -b proteins (designated as PA1a/b) by treating the rhHMGA1a and -b proteins with protein kinase CK2 in the presence of ATP. To examine the sites of phosphorylation induced by $\mathrm{CK} 2$, we also digested the phosphorylated protein with trypsin and analyzed the digestion mixture with on-line LC-MS/MS. Our results confirmed that the majority of phosphorylation occurs in the C-terminal motifs of the two proteins, that is, at Ser98, Ser101, and Ser102 in HMGA1a and at the corresponding residues in HMGA1b (22-24). In addition, low levels of phosphorylation were found for Ser37 in HMGA1b as well as Ser43 and Ser48 in HMGA1a. MALDI-MS results for the tryptic digestion mixtures and the product ion spectra of the phosphorylated peptides are depicted in Figures S3-S5.

CK2-mediated C-terminal phosphorylation did not affect the methylation reaction in a noticeable way regardless of the presence or absence of AT-rich duplex DNA (Figure $3 \mathrm{~A}-\mathrm{C})$, and the phosphorylation led to an only slight decrease in the methylation efficiency of all three AT-hooks in rhHMGA1a and -b in the absence of AT-rich duplex DNA.

Arg25 and Arg23 residues are preferentially methylated by PRMT1 and PRMT3, respectively. To map the methylation sites within the three AT-hooks, we analyzed the methylated peptides by MALDI-MS/MS. The three AThooks, AT1, AT2, and AT3, contain four, three, and three arginine residues, respectively. Our initial results suggested that each individual arginine within the three AT-hooks can adopt at most two methyl groups under different reaction conditions (Table 1). To determine the preferential sites of methylation in these three AT-hooks, we chose the AT-hook peptides with a lower level of methylation for MS/MS studies. First, we recorded the product ion spectrum of the $[\mathrm{M}+\mathrm{H}]^{+}$ion of the monomethylated AT1 peptide (RGRGRPRK, $m / z$ 996.7) from PRMT3-methylated rhHMGA1a (Figure 4). From the fragment ions emanating from backbone 


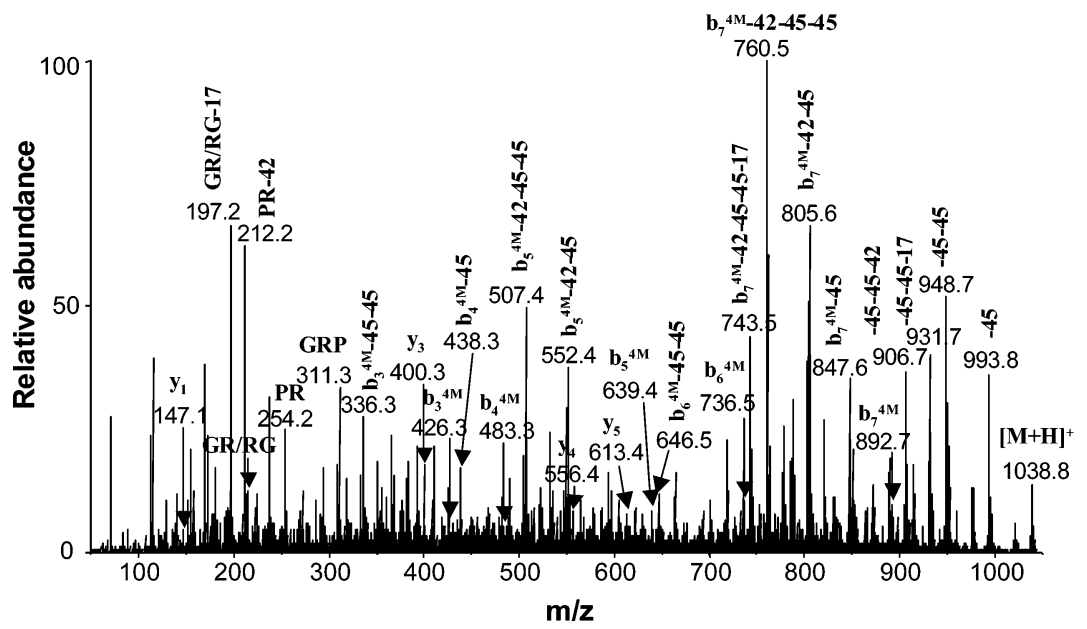

FIGURE 5: Product ion spectrum of the MALDI-produced $[\mathrm{M}+\mathrm{H}]^{+}$ion $\left(\mathrm{m} / \mathrm{z}\right.$ 1038.8) of tetramethylated AT1 peptide $23-30\left(\boldsymbol{R}_{23} \mathrm{G} \boldsymbol{R}_{25^{-}}\right.$ GRPRK) showing that, in the presence of AT-rich duplex DNA, Arg23 and Arg25 in rhHMGA1a are both asymmetrically dimethylated by PRMT3. The symbol "4M" designates fragment ions bearing two dimethylarginines. The neutral losses of 17, 42 , and $45 \mathrm{Da}$ fragments correspond to the losses of $\mathrm{NH}_{3}, \mathrm{C}(\mathrm{NH})_{2}$, and $\left(\mathrm{CH}_{3}\right)_{2} \mathrm{NH}$ groups, respectively (see ref 29).

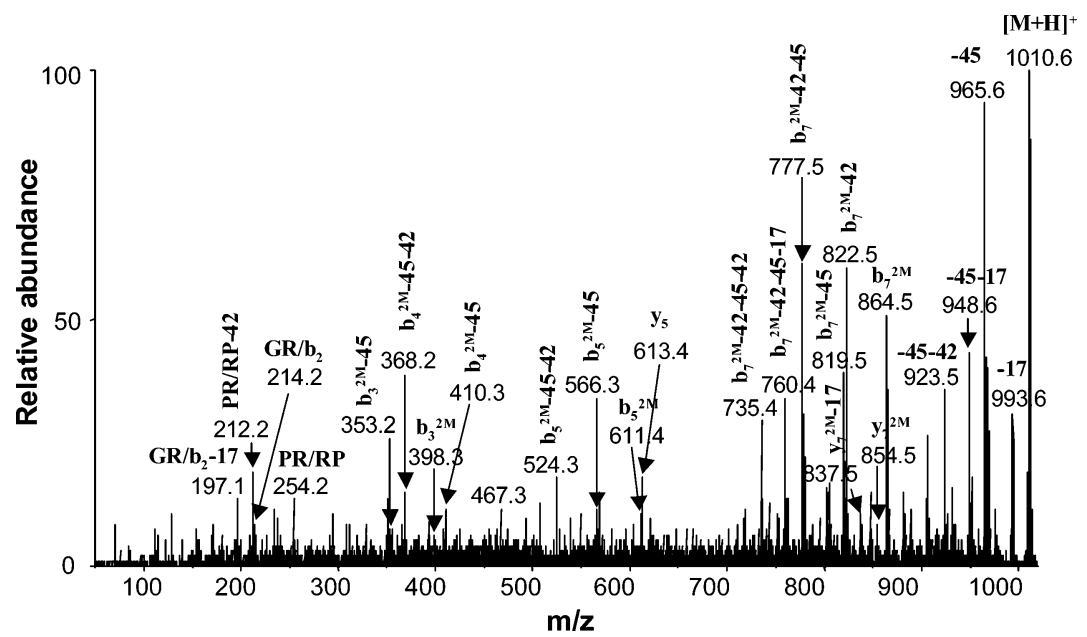

FIGURE 6: Product ion spectrum of the MALDI-produced $[\mathrm{M}+\mathrm{H}]^{+}$ion $(\mathrm{m} / \mathrm{z}, 1010.6)$ of dimethylated AT1 peptide $23-30\left(\mathrm{RG} \boldsymbol{R}_{25^{-}}\right.$ GRPRK) showing that, in the presence of AT-rich duplex DNA, Arg25 in rhHMGA1a is asymmetrically dimethylated by PRMT1. The symbol "2M" designates fragment ions bearing a dimethylarginine. The neutral losses of 17, 42, and 45 Da fragments correspond to the losses of $\mathrm{NH}_{3}, \mathrm{C}(\mathrm{NH})_{2}$, and $\left(\mathrm{CH}_{3}\right)_{2} \mathrm{NH}$ groups, respectively (see ref 29).

cleavages, the methylation site can be located at Arg23. In this context, we observed several $b$ ions carrying one methyl group, namely, $\mathrm{b}_{3}{ }^{\mathrm{M}}(\mathrm{m} / \mathrm{z} 384.3), \mathrm{b}_{4}{ }^{\mathrm{M}}(\mathrm{m} / \mathrm{z} 441.3), \mathrm{b}_{5}{ }^{\mathrm{M}}(\mathrm{m} / \mathrm{z}$ 597.4), and $\mathrm{b}_{7} \mathrm{M}(\mathrm{m} / \mathrm{z}$ 850.6) ions, as well as unmethylated $\mathrm{y}_{3}\left(\mathrm{~m} / \mathrm{z}\right.$ 400.3), $\mathrm{y}_{5}\left(\mathrm{~m} / \mathrm{z}\right.$ 613.4), and $\mathrm{y}_{7}(\mathrm{~m} / \mathrm{z}$ 826.6) ions, indicating that the first arginine residue in the peptide, namely, $\operatorname{Arg} 23$, is the site of methylation. In addition, side chain neutral losses from precursor ion and b/y ions, e.g., the losses of methylamine $\left(\mathrm{CH}_{3} \mathrm{NH}_{2}, 31 \mathrm{Da}\right)$ and monomethylcarbodiimide $\left(\mathrm{CH}_{3} \mathrm{~N}=\mathrm{C}=\mathrm{NH}, 56 \mathrm{Da}\right)(29)$, were consistent with the presence of a monomethylated arginine (MMA) at this position.

Figure 5 showed the product ion spectrum of the protonated ion of tetramethylated AT1 peptide $23-30(\mathrm{~m} / \mathrm{z}$ 1038.8) from PRMT3-methylated rhHMGA1a in the presence of AT-rich duplex DNA. Neutral loss of a dimethylamine $\left[\mathrm{HN}\left(\mathrm{CH}_{3}\right)_{2}, 45 \mathrm{Da}\right]$ was observed, supporting the presence of an aDMA (29). The neutral losses of 31 and 56 Da fragments were not detectable in this spectrum, suggesting the absence of monomethylation in this peptide. We also observed a series of $\mathrm{b}$ ions containing four methyl groups, which include $\mathrm{b}_{3}{ }^{4 \mathrm{M}}(\mathrm{m} / \mathrm{z}, 426.3)$ and $\mathrm{b}_{4}{ }^{4 \mathrm{M}}(\mathrm{m} / \mathrm{z}, 483.3)$ ions and unmodified $\mathrm{y}_{4}\left(\mathrm{~m} / \mathrm{z}\right.$ 556.4) and $\mathrm{y}_{5}(\mathrm{~m} / \mathrm{z}$ 613.4) ions. Therefore, the MALDI-MS/MS results demonstrated that Arg23 and Arg25 are both asymmetrically dimethylated, whereas neither Arg27 nor Arg29 is methylated.

We also examined, by MALDI-MS/MS, dimethylated AT1 peptide 23-30 ( $/ 2 / z$ 1010.6) from PRMT1-methylated rhHMGA1a in the presence of AT-rich duplex DNA (Figure 6 ). The results revealed the neutral loss of 45 but not 31 and $56 \mathrm{Da}$ fragments from the molecular ion and b/y ions, showing that only one arginine was asymmetrically dimethylated in this peptide. In addition, we detected unmodified $\mathrm{y}_{5}$ ion $(\mathrm{m} / \mathrm{z}$ 613.4) and dimethylated $\mathrm{b} / \mathrm{y}$ ions such as $\mathrm{b}_{3}{ }^{2 \mathrm{M}}(\mathrm{m} / \mathrm{z} 398.3), \mathrm{b}_{4}{ }^{2 \mathrm{M}}-45(\mathrm{~m} / \mathrm{z}, 410.3)$, and $\mathrm{y}_{7}{ }^{2 \mathrm{M}}(\mathrm{m} / \mathrm{z}$ 854.5) ions. Thus, Arg 25 is asymmetrically dimethylated in this peptide. For the sample methylated in the absence of ATrich duplex DNA, the tandem mass spectrum of the same peptide ion also indicated that Arg25 was asymmetrically dimethylated (data not shown).

\section{DISCUSSION}

Recently, the PRMT6-mediated methylation of HMGA1a has been studied $(37,38)$. Miranda et al. (37) examined all 
known type I PRMTs for their ability to methylate the recombinant human HMGA1a protein. The results showed that the GST-PRMT6 fusion protein specifically methylates full-length HMGA1a, whereas GST-PRMT1 and GSTPRMT3 proteins methylate truncated the HMGA1a polypeptide more efficiently than the full-length protein. Their results suggested that PRMT6 is a good candidate for the endogenous enzyme responsible for HMGA1a methylation (37). In addition, a more recent study by Sgarra et al. (38) showed that HMGA1a associates with, and is methylated in vivo, by PRMT6; tandem mass spectral data revealed that the second AT-hook was preferentially methylated by this enzyme. Our results confirmed that, at high enzyme:substrate ratios, all three AT-hooks in HMGA1 proteins could be methylated by PRMT6 with the preference of methylation for the second AT-hook.

We further determined the specificities of methylation of HMGA1 proteins catalyzed by PRMT1 and PRMT3. Interestingly, these two enzymes appear to have similar methylation specificities toward the three AT-hooks of HMGA1 proteins. Unlike PRMT6, PRMT1 and PRMT3 methylate HMGA1 proteins principally in the first AT-hook. The three AT-hooks of HMGA1a and HMGA1b share a core sequence of Arg-Gly-Arg-Pro (38). However, both the second and third AT-hooks have a Pro and a Lys flanking the core sequence, while the first AT-hook bears a Gly and an Arg flanking the same core sequence. We speculate that the different flanking residues may account for the three PRMTs' selectivities in methylating arginine residues in the different AT-hooks of the HMGA1 proteins. Therefore, PRMT6 favors the Pro-Arg-Gly-Arg-Pro-Lys sequence in the second (and to a lesser extent in the third) AT-hook, whereas PRMT1 and PRMT3 prefer the Gly-Arg-Gly-Arg-Pro-Arg sequence in the first AT-hook. Although multiple AT-hooks of HMGA1 proteins can be methylated by all three PRMTs that were examined, the different selectivities of these enzymes toward the three AT-hooks indicate that they have the ability to discriminate the subtle differences in substrate sequences. In addition, we suspect that the HMGA1 proteins may assume a certain degree of tertiary structure upon association with PRMTs, and different PRMTs may recognize differently the three AT-hooks of HMGA1 in these protein-protein complexes.

Our tandem mass spectral results showed that Arg25 and Arg23 in HMGA1 proteins are the initial sites of methylation catalyzed by PRMT1 and PRMT3, respectively. Previous studies showed that Arg25 is the major site of methylation in the HMGA1a protein isolated from tumor cells $(16,29$, 39,46 ), whereas the methylation of Arg23 has not yet been found to occur in vivo.

Is PRMT1 the enzyme that methylates HMGA1a protein at Arg25 in vivo? PRMT1 is the most prevalent methyltransferase in mammalian cells with a wide substrate spectrum, and it is responsible for more than $85 \%$ of all arginine methylation reactions (47). The major protein substrates for PRMT1 were identified to be nuclear proteins, such as core histone $\mathrm{H} 4$ (48), heterogeneous nuclear ribonucleoprotein (hnRNP) (49), fibrillarin (50), and nucleolin (51). In our study, we identified another group of nuclear proteins, HMGA1 proteins, as new substrates for PRMT1. Previous results in the localization of PRMT1 were inconsistent with each other, ranging from predominantly nuclear to predominantly cytoplasmic localization (47). The difference in the localization of PRMT1 may reflect the use of different cell lines in which the expressions of substrate proteins to be methylated are different (47). A recent fluorescence recovery after photobleaching (FRAP) study by Herrmann et al. (47) revealed that PRMT1 is highly mobile in both the cytoplasm and nucleus. More interestingly, PRMT1 is trapped in the nucleus by unmethylated substrates such as core histones and hnRNP and is released after it has executed its methylation reaction (47). Taking all of the existing experimental evidence together, we suggest that PRMT1 is a major candidate enzyme for the in vivo monomethylation and asymmetric dimethylation of Arg25 in HMGA1a.

PRMT3 was discovered as an ortholog of PRMT1, and it may function primarily in ribosomal protein methylation (52). These two homologous type I PRMTs differ in the Nterminal domain, where PRMT3 has a putative $\mathrm{C}_{2} \mathrm{H}_{2}$ type zinc-finger motif and a tyrosine phosphorylation consensus sequence (53). Although they both can induce the dimethylation of arginine residues in the RG or RGG consensus sequence, they have different substrate specificity, oligomerization, and subcellular localization (42). PRMT3 has less specific methyltransferase activity than PRMT1, and binding to zinc ion is required for accessing and methylating RNAassociated protein substrates (53). In addition, PRMT3 levels are higher in the cytoplasm than in the nucleus (42). Taken together, PRMT3 seems not to be as a good candidate for methylation of Arg25 as PRMT1.

The HMGA1 proteins act as architectural transcription factors and have been suggested to be a "hub" of nuclear function (2). They participate in a wide variety of nuclear processes ranging from DNA replication and repair to the regulation of gene transcription, mRNA splicing, and the control of integration of retroviruses into the genome $(1,2)$. The diverse biological functions of HMGA1 proteins are not surprising because extensive studies have demonstrated that HMGA1 proteins recognize and modulate the structures of both DNA and chromatin substrates (3).

Although all or only two (second and third AT-hooks) of the three AT-hooks are directly involved in DNA binding depending on the type of DNA substrates that have been examined, the second AT-hook plays a central role in the organization of the protein-DNA complexes (54-57). Our results showed that, upon binding to AT-rich duplex DNA, the efficiencies of in vitro methylation of HMGA1 proteins by PRMT1, PRMT3, and PRMT6 were all markedly reduced (Figure 3). We speculate that the inhibition of methylation by AT-rich duplex DNA may be caused by several factors. First, the three AT-hooks of HMGA1 proteins interact with AT-rich duplex DNA, which induces the formation of secondary or tertiary structure of HMGA1 proteins. Thus, the DNA molecules may physically block the accessibility of the three AT-hooks of the protein substrates to PRMTs. Along this line, the more rigid conformation of HMGA1 induced by DNA binding may lead to difficulty in forming the HMGA1-PRMT complexes, which are required for the execution of methylation. Moreover, the duplex DNA molecules might interact directly with PRMTs, thereby inhibiting the catalytic activities of the PRMTs; however, this possibility can be excluded on the grounds that the duplex DNA with the central $\mathrm{A} \cdot \mathrm{T}$ base pairs being replaced 
with $\mathrm{G} \cdot \mathrm{C}$ base pairs did not affect the in vitro methylation of the rhHMGA1a protein to a noticeable extent.

C-Terminal constitutive phosphorylation and Arg25 methylation in HMGA1a protein have been found to coexist in vivo in many different tumor cell lines $(15,16,29)$. In addition, the phosphorylation of $\mathrm{C}$-terminal serines in rhHMGA1a diminishes its DNA binding affinity $(23,24$, 54). However, our results demonstrated that the C-terminal phosphorylation of HMGA1 proteins by CK2 did not exert any appreciable effect on the in vitro methylation induced by the three PRMTs.

Different biological functions of the two closely related isoform proteins, HMGA1a and HMGA1b, have come to light recently. Banks et al. (17) have demonstrated the PTMs of the two isoforms affect their mode of DNA-protein interactions. Many studies have demonstrated the different in vivo PTM patterns of HMGA1a and HMGA1b isoforms from different tissue culture cell types $(13,17,29)$. In addition, microarray analysis of transcription profiles showed that the two isoforms differentially regulate specific genes (14). Overexpression of HMGA1b, rather than HMGA1a, promotes tumor formation and metastasis in nude mice (14). In keeping with these previous studies, our results illustrated that, upon binding to AT-rich DNA, HMGA1a was a better substrate than HMGA1b for both PRMT1 and PRMT3, regardless of whether the protein is phosphorylated by CK2 prior to the methylation reaction (Figure 3). Noticeably, the methylation of the two isoforms by PRMT6 was almost identical in either the absence or presence of AT-rich duplex DNA.

In conclusion, we have systematically examined the in vitro methylation of recombinant human HMGA1a and HMGA1b proteins by three type I PRMTs under various circumstances. The methylation specificity among the three AT-hooks, the effects of binding with AT-rich duplex DNA, and C-terminal constitutive phosphorylation were investigated. We speculate that PRMT1 is very likely responsible for in vivo monomethylation and asymmetric dimethylation of Arg25 in the first AT-hook of HMGA1a, though other PRMTs might also be involved. The biological function and significance of methylation of HMGA1 proteins as well as the relevant biological events involving certain PRMTs remain unknown. Nevertheless, the findings reported in this study pave the way for future study of the complex network of chromatin proteins and the associated PTM code.

\section{ACKNOWLEDGMENT}

We thank Dr. Songqin Pan at the W. M. Keck Proteomics Laboratory, Center of Plant Cell Biology, University of California, Riverside, CA, for help with MALDI-MS/MS measurements.

\section{SUPPORTING INFORMATION AVAILABLE}

MALDI-MS results of the tryptic peptide mixture of in vitro phosphorylated rhHMGA1a and rhHMGA1b proteins by protein kinase CK2, ESI-MS/MS of monophosphorylated peptide 30-54 of rhHMGA1a, ESI-MS/MS of monophosphorylated peptide $30-43$ of rhHMGA1b, and effects of ATor GC-rich duplex DNA on the level of methylation of three AT-hooks in HMGA1a. This material is available free of charge via the Internet at http://pubs.acs.org.

\section{REFERENCES}

1. Reeves, R. (2004) HMGA proteins: Isolation, biochemical modifications, and nucleosome interactions, Methods Enzymol. $375,297-322$.

2. Reeves, R. (2001) Molecular biology of HMGA proteins: Hubs of nuclear function, Gene 277, 63-81.

3. Reeves, R., and Beckerbauer, L. (2001) HMGI/Y proteins: Flexible regulators of transcription and chromatin structure, Biochim. Biophys. Acta 1519, 13-29.

4. Reeves, R., and Nissen, M. S. (1993) Interaction of high mobility group-I (Y) nonhistone proteins with nucleosome core particles, J. Biol. Chem. 268, 21137-21146.

5. Reeves, R., and Wolffe, A. P. (1996) Substrate structure influences binding of the non-histone protein $\mathrm{HMG}-\mathrm{I}(\mathrm{Y})$ to free nucleosomal DNA, Biochemistry 35, 5063-5074.

6. Hill, D. A., Pedulla, M. L., and Reeves, R. (1999) Directional binding of HMG-I(Y) on four-way junction DNA and the molecular basis for competitive binding with HMG-1 and histone H1, Nucleic Acids Res. 27, 2135-2144.

7. Nissen, M. S., and Reeves, R. (1995) Changes in superhelicity are introduced into closed circular DNA by binding of high mobility group protein I/Y, J. Biol. Chem. 270, 4355-4360.

8. Solomon, M. J., Strauss, F., and Varshavsky, A. (1986) A mammalian high mobility group protein recognizes any stretch of six A $\cdot$ T base pairs in duplex DNA, Proc. Natl. Acad. Sci. U.S.A. $83,1276-1280$.

9. Huth, J. R., Bewley, C. A., Nissen, M. S., Evans, J. N., Reeves, R., Gronenborn, A. M., and Clore, G. M. (1997) The solution structure of an HMG-I(Y)-DNA complex defines a new architectural minor groove binding motif, Nat. Struct. Biol. 4, 657665.

10. Johnson, K. R., Lehn, D. A., Elton, T. S., Barr, P. J., and Reeves, R. (1988) Complete murine cDNA sequence, genomic structure, and tissue expression of the high mobility group protein HMGI(Y), J. Biol. Chem. 263, 18338-18342.

11. Johnson, K. R., Lehn, D. A., and Reeves, R. (1989) Alternative processing of mRNAs encoding mammalian chromosomal highmobility-group proteins HMG-I and HMG-Y, Mol. Cell. Biol. 9, 2114-2123.

12. Sgarra, R., Rustighi, A., Tessari, M. A., Di Bernardo, J., Altamura, S., Fusco, A., Manfioletti, G., and Giancotti, V. (2004) Nuclear phosphoproteins HMGA and their relationship with chromatin structure and cancer, FEBS Lett. 574, 1-8.

13. Edberg, D. D., Adkins, J. N., Springer, D. L., and Reeves, R. (2005) Dynamic and differential in vivo modifications of the isoform HMGA1a and HMGA1b chromatin proteins, J. Biol. Chem. 280, 8961-8973

14. Reeves, R., Edberg, D. D., and Li, Y. (2001) Architectural transcription factor $\mathrm{HMGI}(\mathrm{Y})$ promotes tumor progression and mesenchymal transition of human epithelial cells, Mol. Cell. Biol. $21,575-594$

15. Diana, F., Sgarra, R., Manfioletti, G., Rustighi, A., Poletto, D., Sciortino, M. T., Mastino, A., and Giancotti, V. (2001) A link between apoptosis and degree of phosphorylation of high mobility group A1a protein in leukemic cells, J. Biol. Chem. 276, 1135411361

16. Sgarra, R., Diana, F., Bellarosa, C., Dekleva, V., Rustighi, A., Toller, M., Manfioletti, G., and Giancotti, V. (2003) During apoptosis of tumor cells HMGA1a protein undergoes methylation: Identification of the modification site by mass spectrometry, Biochemistry 42, 3575-3585.

17. Banks, G. C., Li, Y., and Reeves, R. (2000) Differential in vivo modifications of the HMGI(Y) nonhistone chromatin proteins modulate nucleosome and DNA interactions, Biochemistry 39, 8333-8346.

18. Struhl, K. (2001) Gene regulation. A paradigm for precision, Science 293, 1054-1055.

19. Munshi, N., Agalioti, T., Lomvardas, S., Merika, M., Chen, G., and Thanos, D. (2001) Coordination of a transcriptional switch by HMGI(Y) acetylation, Science 293, 1133-1136.

20. Elton, T. S., and Reeves, R. (1986) Purification and postsynthetic modifications of Friend erythroleukemic cell high mobility group protein HMG-I, Anal. Biochem. 157, 53-62.

21. Giancotti, V., Pani, B., D’Andrea, P., Berlingieri, M. T., Di Fiore, P. P., Fusco, A., Vecchio, G., Philp, R., Crane-Robinson, C., Nicolas, R. H., Wright, C. A., and Goodwin, G. H. (1987) Elevated levels of a specific class of nuclear phosphoproteins in cells 
transformed with v-ras and v-mos oncogenes and by cotransfection with c-myc and polyoma middle T genes, EMBO J. 6, 19811987.

22. Palvimo, J., and Linnala-Kankkunen, A. (1989) Identification of sites on chromosomal protein HMG-I phosphorylated by casein kinase II, FEBS Lett. 257, 101-104.

23. Ferranti, P., Malorni, A., Marino, G., Pucci, P., Goodwin, G. H., Manfioletti, G., and Giancotti, V. (1992) Mass spectrometric analysis of the HMGY protein from Lewis lung carcinoma. Identification of phosphorylation sites, J. Biol. Chem. 267, 2248622489.

24. Wang, D. Z., Ray, P., and Boothby, M. (1995) Interleukin 4-inducible phosphorylation of HMG-I(Y) is inhibited by rapamycin, J. Biol. Chem. 270, 22924-22932.

25. Reeves, R., Langan, T. A., and Nissen, M. S. (1991) Phosphorylation of the DNA-binding domain of nonhistone high-mobility group I protein by cdc2 kinase: Reduction of binding affinity, Proc. Natl. Acad. Sci. U.S.A. 88, 1671-1675.

26. Nissen, M. S., Langan, T. A., and Reeves, R. (1991) Phosphorylation by cdc2 kinase modulates DNA binding activity of high mobility group I nonhistone chromatin protein, J. Biol. Chem. 266, 19945-19952.

27. Xiao, D. M., Pak, J. H., Wang, X., Sato, T., Huang, F. L., Chen, H. C., and Huang, K. P. (2000) Phosphorylation of HMG-I by protein kinase $\mathrm{C}$ attenuates its binding affinity to the promoter regions of protein kinase $\mathrm{C}$ gamma and neurogranin/RC3 genes, J. Neurochem. 74, 392-399.

28. McBride, A. E., and Silver, P. A. (2001) State of the Arg: Protein methylation at arginine comes of age, Cell 106, 5-8.

29. Zou, Y., and Wang, Y. (2005) Tandem mass spectrometry for the examination of the posttranslational modifications of high-mobility group A1 proteins: Symmetric and asymmetric dimethylation of Arg 25 in HMGA1a protein, Biochemistry 44, 6293-6301.

30. Gary, J. D., and Clarke, S. (1998) RNA and protein interactions modulated by protein arginine methylation, Prog. Nucleic Acid Res. Mol. Biol. 61, 65-131.

31. Branscombe, T. L., Frankel, A., Lee, J. H., Cook, J. R., Yang, Z., Pestka, S., and Clarke, S. (2001) PRMT5 (Janus kinase-binding protein 1) catalyzes the formation of symmetric dimethylarginine residues in proteins, J. Biol. Chem. 276, 32971-32976.

32. Frankel, A., Yadav, N., Lee, J., Branscombe, T. L., Clarke, S., and Bedford, M. T. (2002) The novel human protein arginine N-methyltransferase PRMT6 is a nuclear enzyme displaying unique substrate specificity, J. Biol. Chem. 277, 3537-3543.

33. Lee, J., Sayegh, J., Daniel, J., Clarke, S., and Bedford, M. T. (2005) PRMT8, a new membrane-bound tissue-specific member of the protein arginine methyltransferase family, J. Biol. Chem. 280, 32890-32896.

34. Bedford, M. T., and Richard, S. (2005) Arginine methylation an emerging regulator of protein function, Mol. Cell 18, 263-272.

35. Lee, J. H., Cook, J. R., Yang, Z. H., Mirochnitchenko, O., Gunderson, S. I., Felix, A. M., Herth, N., Hoffmann, R., and Pestka, S. (2005) PRMT7, a new protein arginine methyltransferase that synthesizes symmetric dimethylarginine, J. Biol. Chem. 280, 3656-3664.

36. Scott, H. S., Antonarakis, S. E., Lalioti, M. D., Rossier, C., Silver, P. A., and Henry, M. F. (1998) Identification and characterization of two putative human arginine methyltransferases (HRMT1L1 and HRMT1L2), Genomics 48, 330-340.

37. Miranda, T. B., Webb, K. J., Edberg, D. D., Reeves, R., and Clarke, S. (2005) Protein arginine methyltransferase 6 specifically methylates the nonhistone chromatin protein HMGA1a, Biochem. Biophys. Res. Commun. 336, 831-835.

38. Sgarra, R., Lee, J., Tessari, M. A., Altamura, S., Spolaore, B., Giancotti, V., Bedford, M. T., and Manfioletti, G. (2006) The AThook of the chromatin architectural transcription factor high mobility group A1a is arginine-methylated by protein arginine methyltransferase 6, J. Biol. Chem. 281, 3764-3772.

39. Jiang, X., and Wang, Y. (2006) Acetylation and phosphorylation of high-mobility group A1 proteins in PC-3 human tumor cells, Biochemistry 45, 7194-7201.

40. Edberg, D. D., Bruce, J. E., Siems, W. F., and Reeves, R. (2004) In vivo posttranslational modifications of the high mobility group a1 a proteins in breast cancer cells of differing metastatic potential, Biochemistry 43, 11500-11515.

41. Lin, W. J., Gary, J. D., Yang, M. C., Clarke, S., and Herschman, H. R. (1996) The mammalian immediate-early TIS21 protein and the leukemia-associated BTG1 protein interact with a proteinarginine N-methyltransferase, J. Biol. Chem. 271, 15034-15044.

42. Tang, J., Gary, J. D., Clarke, S., and Herschman, H. R. (1998) PRMT 3, a type I protein arginine $\mathrm{N}$-methyltransferase that differs from PRMT1 in its oligomerization, subcellular localization, substrate specificity, and regulation, J. Biol. Chem. 273, 1693516945.

43. Reeves, R., and Nissen, M. S. (1999) Purification and assays for high mobility group HMG-I(Y) protein function, Methods Enzymol. 304, 155-188.

44. Zou, Y., Jiang, X., and Wang, Y. (2004) Identification of novel in vivo phosphorylation sites in high mobility group N1 protein from the MCF-7 human breast cancer cells, Biochemistry 43, $6322-6329$.

45. Slama-Schwok, A., Zakrzewska, K., Leger, G., Leroux, Y. Takahashi, M., Kas, E., and Debey, P. (2000) Structural changes induced by binding of the high-mobility group I protein to a mouse satellite DNA sequence, Biophys. J. 78, 2543-2559.

46. Sgarra, R., Diana, F., Rustighi, A., Manfioletti, G., and Giancotti, V. (2003) Increase of HMGA1 a protein methylation is a distinctive characteristic of leukaemic cells induced to undergo apoptosis, Cell Death Differ. 10, 386-389.

47. Herrmann, F., Lee, J., Bedford, M. T., and Fackelmayer, F. O. (2005) Dynamics of human protein arginine methyltransferase 1 (PRMT1) in vivo, J. Biol. Chem. 280, 38005-38010.

48. Strahl, B. D., Briggs, S. D., Brame, C. J., Caldwell, J. A., Koh, S. S., Ma, H., Cook, R. G., Shabanowitz, J., Hunt, D. F., Stallcup, M. R., and Allis, C. D. (2001) Methylation of histone H4 at arginine 3 occurs in vivo and is mediated by the nuclear receptor coactivator PRMT1, Curr. Biol. 11, 996-1000.

49. Wada, K., Inoue, K., and Hagiwara, M. (2002) Identification of methylated proteins by protein arginine $\mathrm{N}$-methyltransferase 1 , PRMT1, with a new expression cloning strategy, Biochim. Biophys. Acta 1591, 1-10.

50. Najbauer, J., Johnson, B. A., Young, A. L., and Aswad, D. W. (1993) Peptides with sequences similar to glycine, arginine-rich motifs in proteins interacting with RNA are efficiently recognized by methyltransferase(s) modifying arginine in numerous proteins, J. Biol. Chem. 268, 10501-10509.

51. Lischwe, M. A., Cook, R. G., Ahn, Y. S., Yeoman, L. C., and Busch, H. (1985) Clustering of glycine and NG,NG-dimethylarginine in nucleolar protein C23, Biochemistry 24, 6025-6028.

52. Swiercz, R., Cheng, D., Kim, D., and Bedford, M. T. (2007) Ribosomal protein rpS2 is hypomethylated in PRMT3-deficient mice, J. Bio. Chem. 282, in press.

53. Frankel, A., and Clarke, S. (2000) PRMT3 is a distinct member of the protein arginine N-methyltransferase family. Conferral of substrate specificity by a zinc-finger domain, J. Biol. Chem. 275, 32974-32982.

54. Schwanbeck, R., Gymnopoulos, M., Petry, I., Piekielko, A., Szewczuk, Z., Heyduk, T., Zechel, K., and Wisniewski, J. R. (2001) Consecutive steps of phosphorylation affect conformation and DNA binding of the chironomus high mobility group A protein, J. Biol. Chem. 276, 26012-26021.

55. Yie, J., Liang, S., Merika, M., and Thanos, D. (1997) Intra- and intermolecular cooperative binding of high-mobility-group protein $\mathrm{I}(\mathrm{Y})$ to the $\beta$-interferon promoter, Mol. Cell. Biol. 17, 3649-3662.

56. Frank, O., Schwanbeck, R., and Wisniewski, J. R. (1998) Protein footprinting reveals specific binding modes of a high mobility group protein I to DNAs of different conformation, J. Biol. Chem. 273, 20015-20020.

57. Piekielko, A., Drung, A., Rogalla, P., Schwanbeck, R., Heyduk, T., Gerharz, M., Bullerdiek, J., and Wisniewski, J. R. (2001) Distinct organization of DNA complexes of various HMGI/Y family proteins and their modulation upon mitotic phosphorylation, J. Biol. Chem. 276, 1984-1992.

BI6024897 